\title{
A chiral self-sorting photoresponsive coordination cage based on overcrowded alkenes
}

\author{
Constantin Stuckhardt ${ }^{1,2}$, Diederik Roke ${ }^{1}$, Wojciech Danowski ${ }^{1}$, Edwin Otten ${ }^{1}$, \\ Sander J. Wezenberg ${ }^{*}$ and Ben L. Feringa ${ }^{*}$
}

\author{
Full Research Paper \\ Address: \\ ${ }^{1}$ Stratingh Institute for Chemistry, University of Groningen, Nijenborgh \\ 4, 9747 AG, Groningen, The Netherlands, ${ }^{2}$ Organisch-Chemisches \\ Institut, University of Münster, Corrensstrasse 40, 48149 Münster, \\ Germany and ${ }^{3}$ Leiden Institute of Chemistry, Leiden University, \\ Einsteinweg 55, 2333 CC, Leiden, The Netherlands \\ Email: \\ Sander J. Wezenberg ${ }^{*}$ - s.j.wezenberg@lic.leidenuniv.nl; \\ Ben L. Feringa* - b.l.feringa@rug.nl \\ * Corresponding author \\ Keywords: \\ coordination cages; molecular motors; molecular switches; \\ overcrowded alkene; palladium
}

Beilstein J. Org. Chem. 2019, 15, 2767-2773.

doi:10.3762/bjoc. 15.268

Received: 05 July 2019

Accepted: 11 October 2019

Published: 15 November 2019

This article is part of the thematic issue "Molecular switches".

Guest Editor: W. Szymanski

(c) 2019 Stuckhardt et al.; licensee Beilstein-Institut. License and terms: see end of document.

\begin{abstract}
In recent years, increasing efforts have been devoted to designing new functional stimuli-responsive supramolecular assemblies. Here, we present three isomeric supramolecular coordination complexes consisting of a $\mathrm{Pd}_{2} \mathrm{~L}_{4}$ stoichiometry. As shown by NMR, $\mathrm{CD}$ and X-ray studies, as well as DFT calculations, these complexes form cage-like structures by chiral self-sorting. Photochromic ligands derived from first generation molecular motors enable light-driven interconversion between the three isomers. Two of the isomers were able to form host-guest complexes opening up new prospects toward stimuli-controlled substrate binding and release.
\end{abstract}

\section{Introduction}

Supramolecular coordination complexes (SCCs) represent a promising class of compounds which have been used in a variety of molecular systems [1-6]. Taking advantage of the vacant cavity inside these complexes, SCCs have been applied in drug delivery [6-8], supramolecular catalysis [9-12], X-ray structure determination $[13,14]$ and stabilization of reactive species [15-17]. The use of reversible metal-ligand coordination bonds gives rise to systems that allow for adaption to external stimuli such as $\mathrm{pH}$, anions, electric potential, concentration and light $[4,8,18-21]$. Using light to dynamically control the shape and function of SCCs is a very promising strategy as it is a noninvasive stimulus that can be easily applied with high spatiotemporal control, without producing any waste. Systems have been reported where photoisomerization of azobenzenederived anions encapsulated in supramolecular palladium complexes caused immediate crystallization [22]. Moreover, azobenzenes have been used to functionalize both the interior [23] and exterior [24] of SCCs to photochemically control guest binding and release. Furthermore, incorporation of dithienylethene into the ligands connecting the metal centers has been used to control host-guest interactions [25-28], structural composition [29], and sol-gel transition [30]. However, 
dithienylethene undergoes a limited structural change upon photoisomerization and, up to now, photoswitchable ligands based on other types of photochromic switches have not been reported in the literature.

In chiral self-sorting SCCs, either homo- or heterochiral complexes are formed exclusively through high fidelity recognition of the components within the complex [31-33]. The formation of such complexes with high selectivity and well-defined chirality is essential for the application of SCCs towards chiral recognition and sensing [34-37]. To the best of our knowledge no self-sorted responsive SCCs have been reported so far.

Molecular motors based on overcrowded alkenes are unique photoswitches that are able to undergo unidirectional rotation upon irradiation with light [38-40]. Moreover, they can be used as chiroptical multistate switches to control various functions in areas such as catalysis [41-43], soft materials [43-45] and supramolecular chemistry $[46,47]$. Employing molecular motors as ligands in SCCs provides an interesting strategy to form responsive coordination complexes, as they feature a large geometric change upon switching [47].

Herein, we report a photoresponsive coordination cage with ligands based on a first generation molecular motor (Figure 1).
Cages with a $\mathrm{Pd}_{2} \mathrm{~L}_{4}$ composition are formed from bidentate bispyridyl ligands and Pd(II) ions with a square planar geometry, which have been widely studied [6,48-50]. The photochromic ligands can be switched between three states, forming separate discrete cage complexes, allowing cage-to-cage transformations (Scheme 1). Interestingly, only homochiral cages are formed revealing that a chiral self-sorting process takes place. In addition, two of the cage isomers can bind a tosylate anion in solution by formation of a host-guest complex.

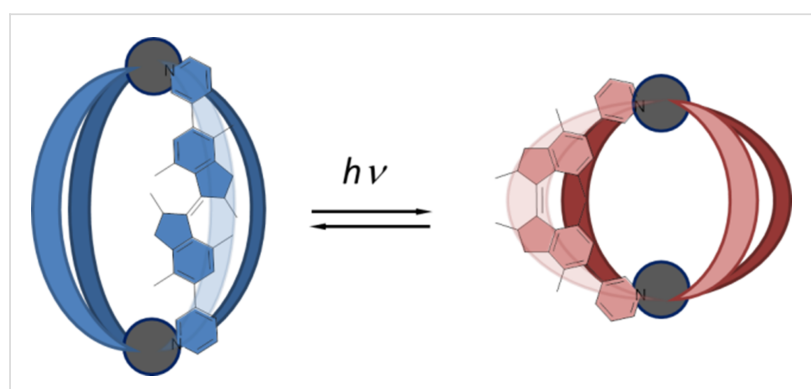

Figure 1: Schematic representation of a photoresponsive cage with ligands based on overcrowded alkenes.

\section{Results and Discussion}

Ligands $Z$-1 and $E$-1 (Scheme 1) were synthesized by a Suzuki cross-coupling reaction of 3-pyridinylboronic acid with an $E / Z$

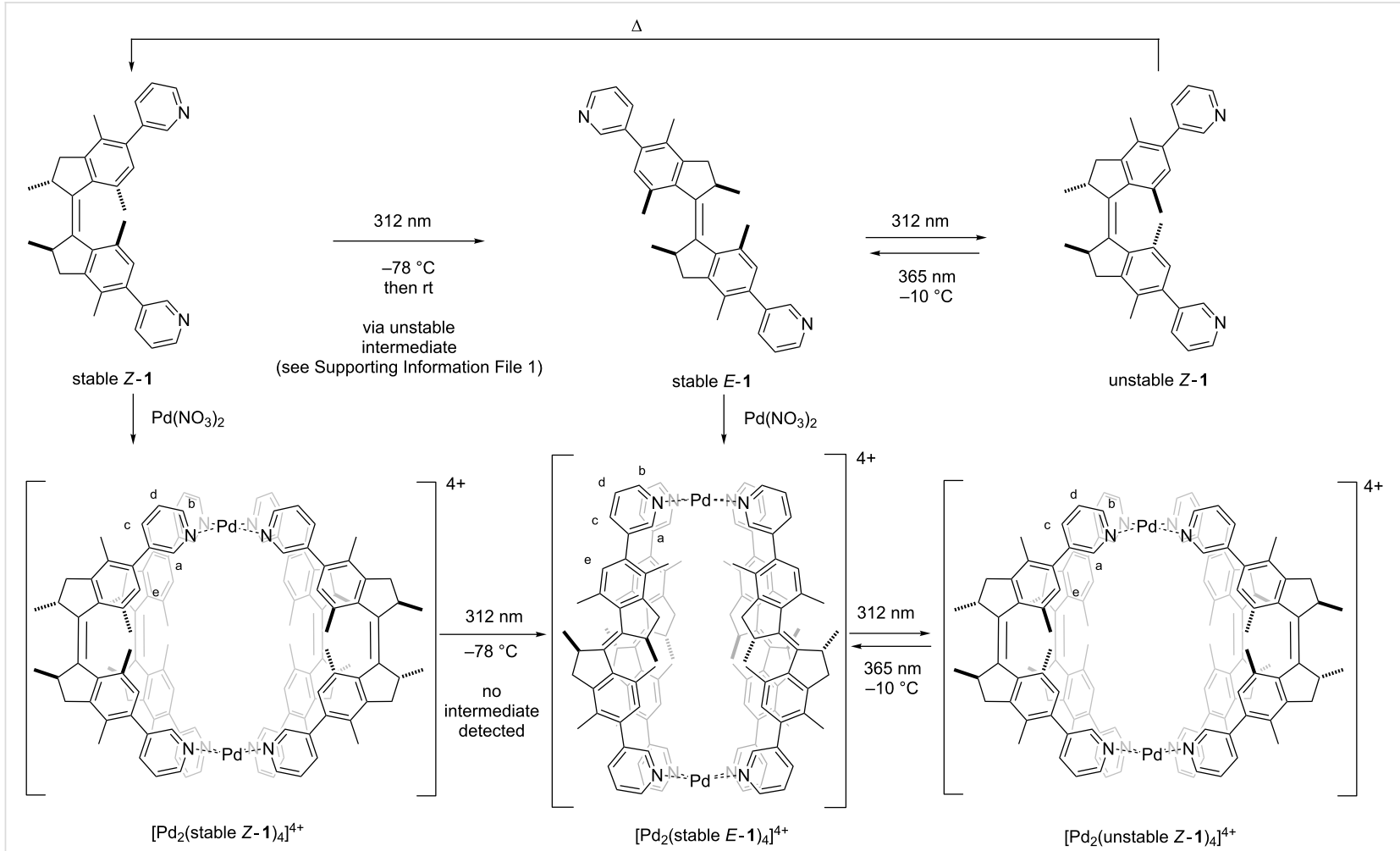

Scheme 1: Cage formation of overcrowded alkene switches $E / Z-1$ and their isomerization behavior. Note that the intermediate unstable $E-1$ is not shown; due to the low barrier of thermal helix inversion and therefore fast isomerization to the corresponding stable isomer. 
mixture of reported overcrowded alkene precursors [51] (see Supporting Information File 1 for full experimental details). Heating a 2:1 mixture of ligands $(S, S)-Z-1$ or $(S, S)-E-\mathbf{1}$ with $\operatorname{Pd}\left(\mathrm{NO}_{3}\right)_{2}$ in acetonitrile at reflux led to the quantitative formation of cage $\mathrm{Pd}_{2}(\text { stable } Z-1)_{4}$ or $\mathrm{Pd}_{2}(\text { stable } E-\mathbf{1})_{4}$, respectively, as evidenced by ${ }^{1} \mathrm{H}$ NMR, DOSY and HRMS. The ${ }^{1} \mathrm{H}$ NMR signals of the pyridine moieties of the ligands $\left(\mathrm{H}_{\mathrm{a}-\mathrm{d}}\right)$ in the assembled cages are shifted downfield compared to those of the free ligands, as expected due to metal coordination (Figure 2) [28]. As the ligand exchange in $\mathrm{Pd}_{2} \mathrm{~L}_{4}$ complexes is slow on the NMR timescale, the discrete signals do not represent an average of quickly interconverting isomers $[52,53]$. The formation of cage complexes using a racemic mixture of ligands stable $Z-\mathbf{1}$ or stable $E-\mathbf{1}$, resulted in the exact same ${ }^{1} \mathrm{H}$ NMR spectrum as was obtained with the enantiopure ligands. Using a racemic mixture of ligands, four different diastereomeric cages can be formed $\left((S, S)_{4},(S, S)_{3}(R, R),(S, S)_{2}(R, R)_{2}\right.$ and $(S, S)(R, R)(S, S)(R, R)$ and their enantiomeric pairs). However, in both cases, only one set of signals is observed, which is a strong indication that only one species with high symmetry is formed by chiral self-sorting without any sign of the formation of diastereomeric mixtures. To further confirm the self-sorting behavior of these cage structures, CD spectroscopy was performed. A linear dependence of $C D$ amplitude on the ee of ligand stable Z-1 was found, which can be expected when the homochiral enantiomers of cage structure $\mathrm{Pd}_{2}(\text { stable } Z-1)_{4}$ are the only optically active species in solution (Figure S1, Supporting Information File 1).

Additionally, DOSY NMR spectroscopy revealed that the signals correspond to a single type of assembly in each case (see Supporting Information File 1, section 2). The measured diffusion coefficients $\left(D=8.7 \times 10^{-10} \mathrm{~m}^{2} \mathrm{~s}^{-1}\right.$ for $\mathrm{Pd}_{2}$ (stable $Z-1)_{4}$ and $D=7.9 \times 10^{-10} \mathrm{~m}^{2} \mathrm{~s}^{-1}$ for cage $\mathrm{Pd}_{2}(\text { stable } E-\mathbf{1})_{4}$ in $\mathrm{CD}_{3} \mathrm{CN}$ at $23{ }^{\circ} \mathrm{C}$ ) can be translated into hydrodynamic radii of $r_{\mathrm{H}}=7.2 \AA$ for $\mathrm{Pd}_{2}(\text { stable } Z \text {-1 })_{4}$ and $r_{\mathrm{H}}=8.0 \AA$ for $\mathrm{Pd}_{2}($ stable $E-1)_{4}$ by using the Stokes-Einstein equation [54]. By means of ESI high-resolution mass spectrometry, we were able to verify the $\mathrm{Pd}_{2} \mathrm{~L}_{4}$ constitution of both cages. The HRMS spectrum of $\mathrm{Pd}_{2}$ (stable $\left.Z-1\right)_{4}$ shows the signals for the cations $\left[\mathrm{Pd}_{2}(\right.$ stable $\left.Z-1)_{4}\left(\mathrm{NO}_{3}\right)_{3}\right]^{+},\left[\mathrm{Pd}_{2}(\text { stable } Z-1)_{4}\left(\mathrm{NO}_{3}\right)_{2}\right]^{2+},\left[\mathrm{Pd}_{2}(\right.$ stable $\left.Z-1)_{4}\left(\mathrm{NO}_{3}\right)\right]^{3+},\left[\mathrm{Pd}_{2}(\text { stable } Z-\mathbf{1})_{4}\right]^{4+}$ (Figure 3). For $\mathrm{Pd}_{2}($ stable $E-1)_{4}$, the peaks corresponding to the cations $\left[\mathrm{Pd}_{2}(\right.$ stable $\left.E-\mathbf{1})_{4}\left(\mathrm{NO}_{3}\right)_{2}\right]^{2+}$ and $\left[\mathrm{Pd}_{2}(\text { stable } E-\mathbf{1})_{4}\left(\mathrm{NO}_{3}\right)\right]^{3+}$ were observed (Figure 3). For both isomers, the experimental isotopic patterns and exact $\mathrm{m} / \mathrm{z}$ values match the simulated patterns.

A single crystal of $\mathrm{Pd}_{2}(\text { stable } E-\mathbf{1})_{4}$ formed from a racemic mixture of ligand $E-\mathbf{1}$ suitable for X-ray structure determination was grown by vapor diffusion of a 1:1 mixture of benzene and diethyl ether into a solution of the cage in a 1:1 mixture of acetonitrile and chloroform. The crystal structure shows cage structures with a $\mathrm{Pd}_{2} \mathrm{~L}_{4}$ stoichiometry with one $\mathrm{NO}_{3}{ }^{-}$counterion and one molecule of acetonitrile located inside each cage. In addition, a chloride ion is located close to the metal centers outside of the cage. This counterion most likely originates from the solvent, as chloroform can contain considerable amounts of $\mathrm{HCl}$. The additional anions required to balance the charge of the tetracationic $\mathrm{Pd}_{2} \mathrm{~L}_{4}$ cage could not be unambiguously located in the difference Fourier map (see Supporting Information File 1 for details). The structure belongs to the $P 4 / n$ space group and the unit cell is occupied by a pair of enantiomeric cages in

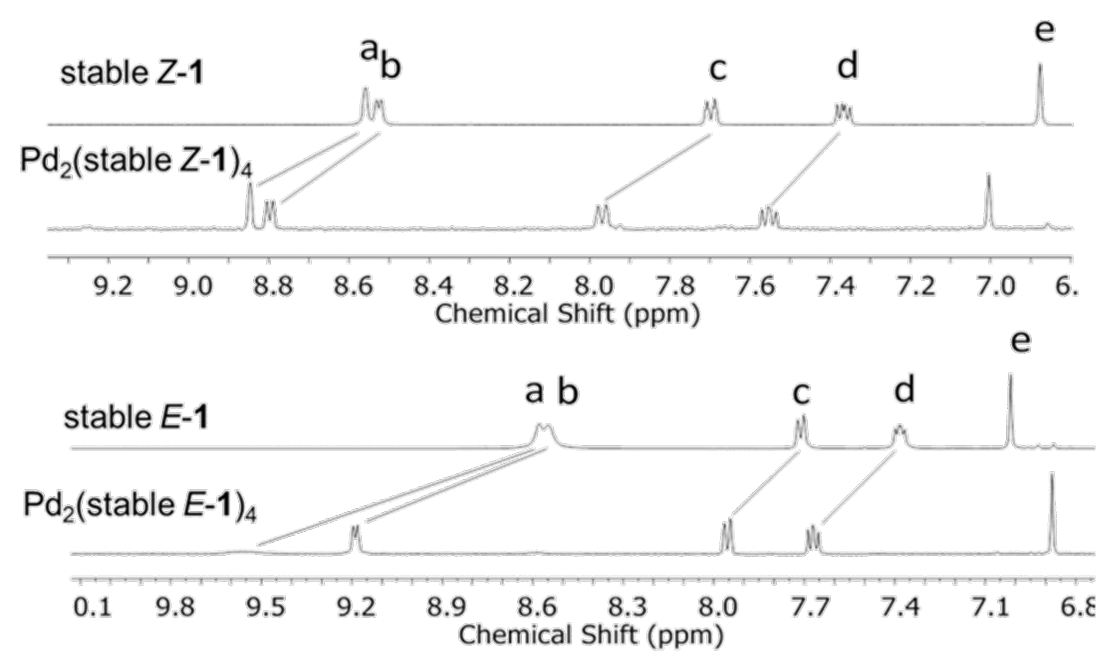

Figure 2: Aromatic region of stacked ${ }^{1} \mathrm{H}$ NMR spectra (in $\mathrm{CD}_{3} \mathrm{CN}$ ) of stable $Z$-1 and cage complex $\mathrm{Pd}_{2}(\mathrm{stable} Z$-1) 4 (top) and $E$-1 and cage complex $\mathrm{Pd}_{2}(\text { stable } E-1)_{4}$ (bottom). 

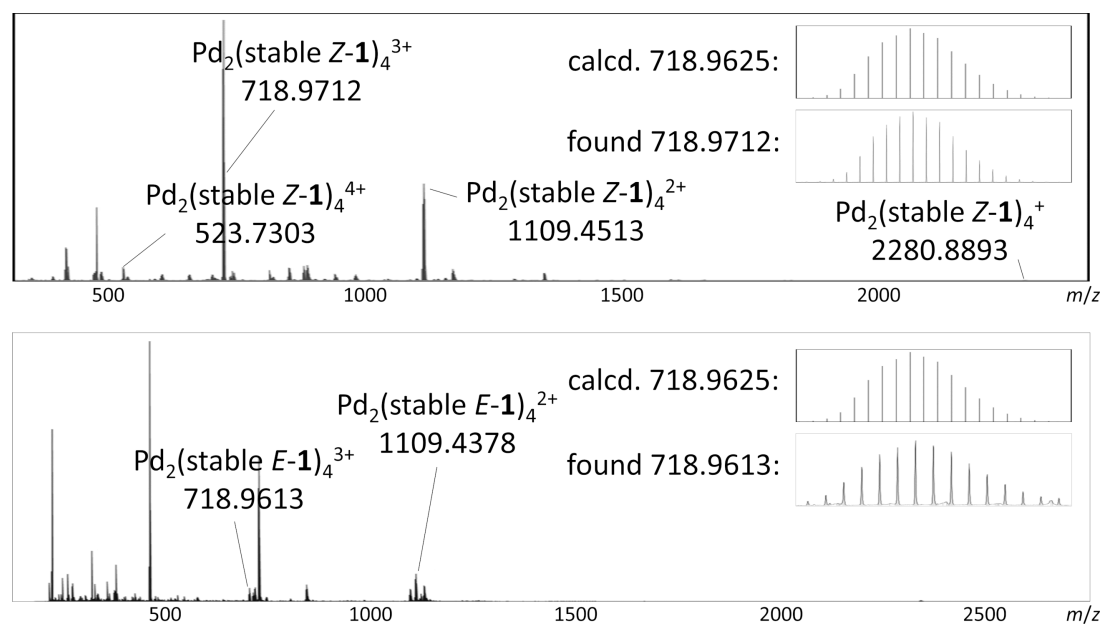

Figure 3: HRMS spectra of cage complex $\mathrm{Pd}_{2}(\text { stable } Z-1)_{4}$ (top) and cage complex $\mathrm{Pd}_{2}$ (stable $\left.E-1\right)_{4}$ (bottom); Insets: comparison of simulated and measured isotopic patterns of $\mathrm{Pd}_{2} \mathrm{~L}_{4}\left(\mathrm{NO}_{3}\right)^{3+}$ ions.

which the Pd-Pd axis of each cage is located at the 4-fold rotation axis. This means that the cage structure is made up with exclusively $(R, R)$ or $(S, S)$ enantiomer of the ligand and that the elementary cell is built from the racemic pair of cages.

DFT calculations were performed to gain insight in the selfsorting behavior of cages $\mathrm{Pd}_{2}(\text { stable } Z-1)_{4}$ and $\mathrm{Pd}_{2}(\text { stable } E \text {-1 })_{4}$. The structures of all possible cage diastereomers were optimized using B3LYP/6-31G(d) for C,H,N and LANL2DZ with ECP for Pd in the gas phase without counter ions. The optimized structure of $\mathrm{Pd}_{2}(\text { stable } E-\mathbf{1})_{4}$ is in good agreement with the solved X-ray structure (Figure 4). Moreover, the calculations revealed that the homochiral cage $\mathrm{Pd}_{2}((S, S) \text {-stable } E-\mathbf{1})_{4}$ (and its enantiomer) are energetically favored by at least $61 \mathrm{~kJ} \mathrm{~mol}^{-1}$ compared to the other possible diastereomers (Table S1, Supporting Information File 1). Similar calculations on the diastereomers of $\mathrm{Pd}_{2}(\text { stable } Z-\mathbf{1})_{4}$ revealed that the homochiral cage diastereomers $\operatorname{Pd}_{2}((S, S) \text {-stable } Z \text {-1 })_{4}$ are energetically favored as well, by at least $19 \mathrm{~kJ} \mathrm{~mol}^{-1}$ (Table S2, Supporting Information File 1). These calculations support that these cages are formed by chiral narcissistic self-sorting.

Next, we were interested in the guest binding abilities of cages $\mathrm{Pd}_{2}$ (stable $\left.Z-\mathbf{1}\right)_{4}$ and $\mathrm{Pd}_{2}(\text { stable } E-\mathbf{1})_{4}$. The tosylate anion was chosen as it has the appropriate size to fit inside the cages. A Job plot analysis revealed a 1:1 binding stoichiometry between both cage isomers and $\mathrm{OTs}^{-}$(Figures S3-S5, Supporting Information File 1), which corresponds to the model in which OTs ${ }^{-}$ serves as a guest molecule which is encapsulated inside the cages $[55,56] .{ }^{1} \mathrm{H}$ NMR titrations with tetrabutylammonium tosylate revealed that both cages are able to bind $\mathrm{OTs}^{-}$, showing similar binding strengths $\left(K_{\mathrm{B}}=1604 \pm 39 \mathrm{M}^{-1}\right.$ for $\mathrm{Pd}_{2}$ (stable $Z-1)_{4} ; K_{\mathrm{B}}=1758 \pm 39 \mathrm{M}^{-1}$ for $\mathrm{Pd}_{2}(\text { stable } E-\mathbf{1})_{4}$ at $\left.293 \mathrm{~K}\right)$.

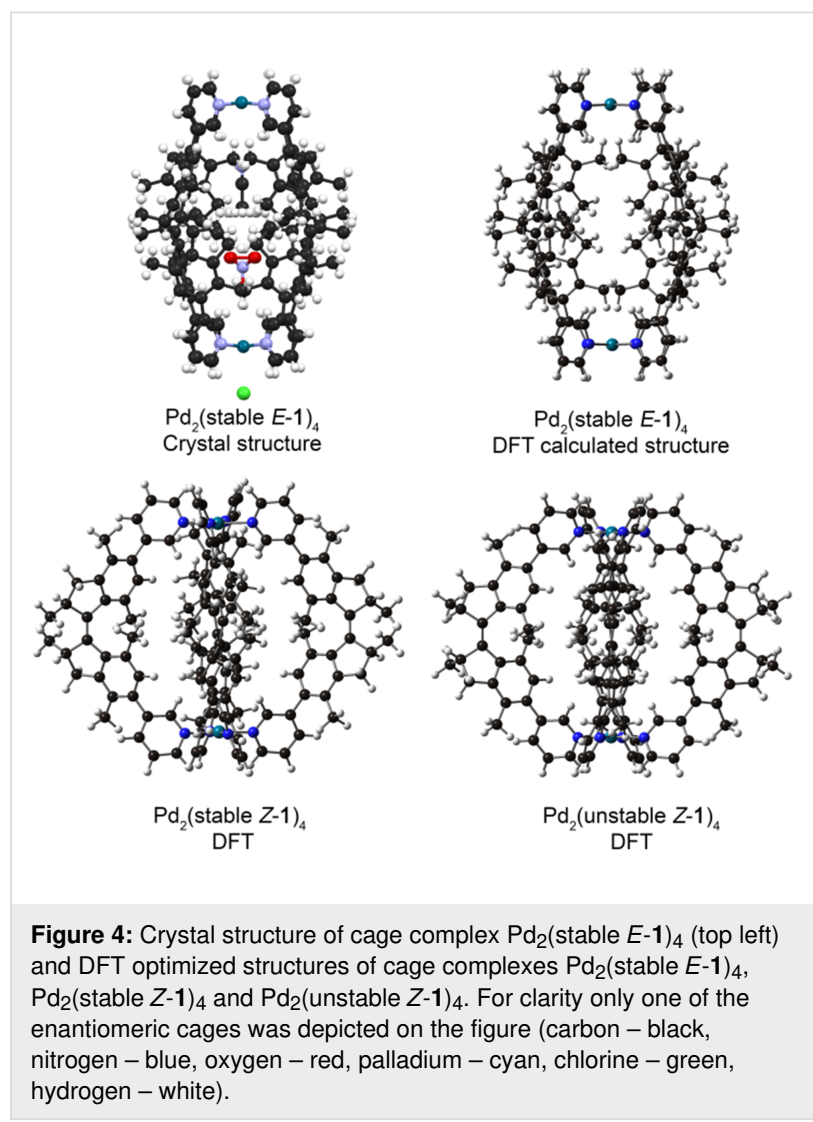

Finally, the photochemical and thermal isomerization behavior of the complexes was studied. Initially, the behavior of ligand $\mathbf{1}$ was studied by UV-vis and NMR spectroscopy, showing similar behavior as related first generation molecular motors (see Supporting Information File 1 for full details). Irradiation with $312 \mathrm{~nm}$ light at $-70{ }^{\circ} \mathrm{C}$ isomerizes stable $Z-\mathbf{1}$ to unstable $E$-1, which undergoes a thermal helix inversion (THI) when warmed 
to room temperature to form stable $E$-1. The second half of the rotation cycle is similar, as irradiation with $312 \mathrm{~nm}$ light isomerizes stable $E$-1 to unstable $Z$-1, which undergoes THI to form stable $Z$-1 when left for several days at room temperature.

Subsequently, the photochemical and thermal isomerizations of cages $\mathrm{Pd}_{2}(\text { stable } Z \text {-1 })_{4}$ and $\mathrm{Pd}_{2}(\text { stable } E-\mathbf{1})_{4}$ were followed by ${ }^{1} \mathrm{H}$ NMR studies (Figure 5). Irradiation of $\mathrm{Pd}_{2}(\text { stable } Z-\mathbf{1})_{4}$ in a $\mathrm{CD}_{3} \mathrm{CN} / \mathrm{CD}_{2} \mathrm{Cl}_{2} 1: 1$ mixture at $312 \mathrm{~nm}$ at $-70{ }^{\circ} \mathrm{C}$ was performed to isomerize ligand stable $Z-\mathbf{1}$ to unstable $E-\mathbf{1}$ (vide infra), followed by allowing the sample to warm to room temperature to form stable $E-\mathbf{1}$ (Figure 5ii). The ${ }^{1} \mathrm{H}$ NMR spectrum of this newly formed complex is identical to the spectrum of $\mathrm{Pd}_{2}$ (stable $E$-1 $)_{4}$ prepared directly from $E$-1 (Figure 5iii), showing that cage $\mathrm{Pd}_{2}(\text { stable } Z-\mathbf{1})_{4}$ is effectively converted to $\mathrm{Pd}_{2}$ (stable $\left.E-\mathbf{1}\right)_{4}$. An intermediate complex containing unstable $E-1$ ligands was not observed, even at low temperatures, most likely due to the low barrier for THI of this isomer. Conversion of cage $\mathrm{Pd}_{2}(\text { stable } E-\mathbf{1})_{4}$ to $\mathrm{Pd}_{2}(\text { unstable } Z-\mathbf{1})_{4}$ by photochemical $E / Z$ isomerization of ligand stable $E-\mathbf{1}$ to unstable $Z-\mathbf{1}$ was performed by irradiation of a sample of $\mathrm{Pd}_{2}(\text { stable } E-\mathbf{1})_{4}$ at $312 \mathrm{~nm}$ at $-20{ }^{\circ} \mathrm{C}$ (Figure 5iv). Signals of cage $\mathrm{Pd}_{2}(\text { stable Z-1 })_{4}$ disappeared and the formation of a new set of signals was observed. DOSY NMR confirmed the formation of an assembly with a hydrodynamic radius which was similar to that of the cage $\mathrm{Pd}_{2}(\text { stable } Z-1)_{4}$. Precipitation of the metal centers in this assembly using tetrabutylammonium glutarate liberates the ligands and they were identified as unstable Z-1. Combined, these results confirm that the photogenerated complex is indeed $\mathrm{Pd}_{2}$ (unstable $\left.Z-1\right)_{4}$. Subsequent irradiation of this sample containing $\mathrm{Pd}_{2}$ (unstable $\left.Z-\mathbf{1}\right)_{4}$ at $-20{ }^{\circ} \mathrm{C}$ at $365 \mathrm{~nm}$ converts the unstable $Z$-1 ligands back to stable $E$-1, reforming $\mathrm{Pd}_{2}$ (stable
$E-1)_{4}$ (Figure 5v). These experiments highlight the reversible formation of $\mathrm{Pd}_{2}$ (unstable $\left.Z-1\right)_{4}$ through photochemical $E / Z$ isomerization of the ligands.

On the other hand, allowing the THI of ligands unstable $Z-1$ in cage $\mathrm{Pd}_{2}$ (unstable $\left.Z-\mathbf{1}\right)_{4}$ to take place by leaving the solution at room temperature for $5 \mathrm{~d}$ did not lead to the formation of $\mathrm{Pd}_{2}$ (stable Z-1) $)_{4}$, but to disassembly of the cage and formation of ill-defined complexes. Precipitation of the metal centers in these complexes identified the ligands as a mixture of both stable $Z$-1 and stable $E$-1 (originating from the PSS mixture), indicating that the THI does take place. A possible explanation could be that the mixture of stable $Z-\mathbf{1}$ and stable $E-\mathbf{1}$ does not form separate well-defined cage structures, but forms mixed complexes.

\section{Conclusion}

In summary, a new photoresponsive supramolecular coordination complex based on overcrowded alkenes is presented, allowing switching between three different cage structures. Interestingly, the cage structures with $\mathrm{Pd}_{2} \mathrm{~L}_{4}$ constitution were shown to be homochiral, forming single diastereomers as evident from NMR, CD and X-ray analysis, supported by DFT calculations. Additionally, the cage structures were able to bind $\mathrm{OTs}^{-}$inside their cavity. Although photoswitching affords a large geometric change of the ligands, only minor changes were observed in binding constants of the different cage structures. These results show that by incorporation of overcrowded alkenes into SCCs the geometry of cage structures can be controlled by light. Different designs might be considered to translate these geometrical changes to changes in properties such as guest binding affinity and selectivity.

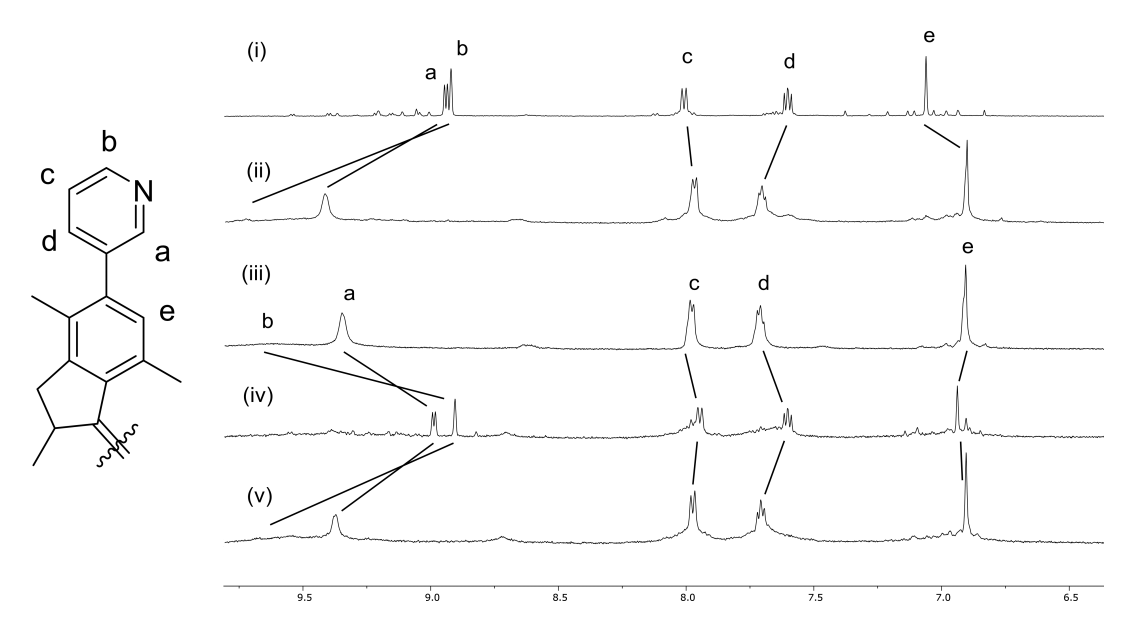

Figure 5: Aromatic region of stacked ${ }^{1} \mathrm{H}$ NMR spectra $\left(\mathrm{CD}_{3} \mathrm{CN} / \mathrm{CD}_{2} \mathrm{Cl}_{2} 1: 1\right)$ of i) $\mathrm{Pd}_{2}(\text { stable } Z-1)_{4}$; ii) $\mathrm{Pd}$ (stable $\left.E-1\right)_{4}$ generated by irradiation of $\mathrm{Pd}_{2}(\text { stable } Z-1)_{4}$ at $312 \mathrm{~nm}$; iii) $\mathrm{Pd}_{2}(\text { stable } E-1)_{4}$ prepared directly from ligand stable $E-1$; iv) $\mathrm{Pd}_{2}(\text { unstable } Z-1)_{4}$ generated by irradiation of $\mathrm{Pd}_{2}(\mathrm{stable}$ $E-1)_{4}$ at $312 \mathrm{~nm}$ and $\left.v\right) \mathrm{Pd}_{2}(\text { stable } E-1)_{4}$ generated by irradiation of $\mathrm{Pd}_{2}(\text { unstable } Z-1)_{4}$ at $365 \mathrm{~nm}$. 


\section{Supporting Information}

\section{Supporting Information File 1}

Experimental procedures, compound characterization, $\mathrm{CD}$ spectroscopy, binding studies, NMR studies of the photochemical and thermal isomerizations, X-ray crystallography, computational details and Cartesian coordinates of DFT optimized structures. [https://www.beilstein-journals.org/bjoc/content/ supplementary/1860-5397-15-268-S1.pdf]

\section{Acknowledgements}

Financial support from the Ministry of Education, Culture and Science (Gravitation program 024.001.035) and European Research Council (Advanced Investigator Grant No. 694345 to B.L.F.) are gratefully acknowledged. We would like to thank the Center for Information Technology of the University of Groningen for their support and for providing access to the Peregrine high performance computing cluster.

\section{ORCID ${ }^{\circledR} \mathrm{iDs}$}

Edwin Otten - https://orcid.org/0000-0002-5905-5108 Ben L. Feringa - https://orcid.org/0000-0003-0588-8435

\section{References}

1. Cook, T. R.; Zheng, Y.-R.; Stang, P. J. Chem. Rev. 2013, 113, 734-777. doi:10.1021/cr3002824

2. Smulders, M. M. J.; Riddell, I. A.; Browne, C.; Nitschke, J. R. Chem. Soc. Rev. 2013, 42, 1728-1754. doi:10.1039/c2cs35254k

3. Cook, T. R.; Stang, P. J. Chem. Rev. 2015, 115, 7001-7045. doi:10.1021/cr5005666

4. Harris, K.; Fujita, D.; Fujita, M. Chem. Commun. 2013, 49, 6703-6712. doi:10.1039/c3cc43191f

5. Han, M.; Engelhard, D. M.; Clever, G. H. Chem. Soc. Rev. 2014, 43, 1848-1860. doi:10.1039/c3cs60473j

6. Schmidt, A.; Casini, A.; Kühn, F. E. Coord. Chem. Rev. 2014, 275, 19-36. doi:10.1016/j.ccr.2014.03.037

7. Ma, Z.; Moulton, B. Coord. Chem. Rev. 2011, 255, 1623-1641. doi:10.1016/j.ccr.2011.01.031

8. Lewis, J. E. M.; Gavey, E. L.; Cameron, S. A.; Crowley, J. D. Chem. Sci. 2012, 3, 778-784. doi:10.1039/c2sc00899h

9. Vriezema, D. M.; Comellas Aragonès, M.; Elemans, J. A. A. W.; Cornelissen, J. J. L. M.; Rowan, A. E.; Nolte, R. J. M. Chem. Rev. 2005, 105, 1445-1490. doi:10.1021/cr0300688

10. Pluth, M. D.; Bergman, R. G.; Raymond, K. N. Acc. Chem. Res. 2009, 42, 1650-1659. doi:10.1021/ar900118t

11. Yoshizawa, M.; Klosterman, J. K.; Fujita, M. Angew. Chem., Int. Ed. 2009, 48, 3418-3438. doi:10.1002/anie.200805340

12. Kaphan, D. M.; Levin, M. D.; Bergman, R. G.; Raymond, K. N.; Toste, F. D. Science 2015, 350, 1235-1238. doi:10.1126/science.aad3087

13. Inokuma, Y.; Yoshioka, S.; Ariyoshi, J.; Arai, T.; Hitora, Y.; Takada, K.; Matsunaga, S.; Rissanen, K.; Fujita, M. Nature 2013, 495, 461-466. doi:10.1038/nature11990
14. Yan, K.; Dubey, R.; Arai, T.; Inokuma, Y.; Fujita, M. J. Am. Chem. Soc. 2017, 139, 11341-11344. doi:10.1021/jacs.7b06607

15. Ziegler, M.; Brumaghim, J. L.; Raymond, K. N. Angew. Chem., Int. Ed. 2000, 39, 4119-4121.

doi:10.1002/1521-3773(20001117)39:22<4119::aid-anie4119>3.0.co;21

16. Kawano, M.; Kobayashi, Y.; Ozeki, T.; Fujita, M. J. Am. Chem. Soc. 2006, 128, 6558-6559. doi:10.1021/ja0609250

17. Mal, P.; Breiner, B.; Rissanen, K.; Nitschke, J. R. Science 2009, 324, 1697-1699. doi:10.1126/science.1175313

18. McConnell, A. J.; Wood, C. S.; Neelakandan, P. P.; Nitschke, J. R. Chem. Rev. 2015, 115, 7729-7793. doi:10.1021/cr500632f

19. Mahata, K.; Frischmann, P. D.; Würthner, F. J. Am. Chem. Soc. 2013, 135, 15656-15661. doi:10.1021/ja4083039

20. Scherer, M.; Caulder, D. L.; Johnson, D. W.; Raymond, K. N. Angew. Chem., Int. Ed. 1999, 38, 1587-1592. doi:10.1002/(sici)1521-3773(19990601)38:11<1587::aid-anie1587>3.0 $\mathrm{co} ; 2-r$

21. Mal, P.; Schultz, D.; Beyeh, K.; Rissanen, K.; Nitschke, J. R. Angew. Chem., Int. Ed. 2008, 47, 8297-8301. doi:10.1002/anie.200803066

22. Clever, G. H.; Tashiro, S.; Shionoya, M. J. Am. Chem. Soc. 2010, 132, 9973-9975. doi:10.1021/ja103620z

23. Murase, T.; Sato, S.; Fujita, M. Angew. Chem., Int. Ed. 2007, 46, 5133-5136. doi:10.1002/anie.200700793

24. Park, J.; Sun, L.-B.; Chen, Y.-P.; Perry, Z.; Zhou, H.-C. Angew. Chem., Int. Ed. 2014, 53, 5842-5846. doi:10.1002/anie.201310211

25. Feringa, B. L.; Browne, W. R. Molecular Switches, 2nd ed.; Wiley-VCH Verlag GmbH \& Co. KGaA: Weinheim, Germany, 2011; Vol. 1.

26. Irie, M.; Fukaminato, T.; Matsuda, K.; Kobatake, S. Chem. Rev. 2014, 114, 12174-12277. doi:10.1021/cr500249p

27. Tian, H.; Yang, S. Chem. Soc. Rev. 2004, 33, 85-97. doi:10.1039/b302356g

28. Han, M.; Michel, R.; He, B.; Chen, Y.-S.; Stalke, D.; John, M.; Clever, G. H. Angew. Chem., Int. Ed. 2013, 52, 1319-1323. doi:10.1002/anie.201207373

29. Han, M.; Luo, Y.; Damaschke, B.; Gómez, L.; Ribas, X.; Jose, A.; Peretzki, P.; Seibt, M.; Clever, G. H. Angew. Chem., Int. Ed. 2016, 55, 445-449. doi:10.1002/anie.201508307

30. Wei, S.-C.; Pan, M.; Fan, Y.-Z.; Liu, H.; Zhang, J.; Su, C.-Y. Chem. - Eur. J. 2015, 21, 7418-7427. doi:10.1002/chem.201406517

31. Safont-Sempere, M. M.; Fernandez, G.; Würthner, F. Chem. Rev. 2011, 111, 5784-5814. doi:10.1021/cr100357h

32. He, Z.; Jiang, W.; Schalley, C. A. Chem. Soc. Rev. 2015, 44, 779-789. doi:10.1039/c4cs00305e

33. Jędrzejewska, H.; Szumna, A. Chem. Rev. 2017, 117, 4863-4899. doi:10.1021/acs.chemrev.6b00745

34. Huang, W.-H.; Zavalij, P. Y.; Isaacs, L. Angew. Chem., Int. Ed. 2007, 46, 7425-7427. doi:10.1002/anie.200702189

35. Haino, T.; Shio, H.; Takano, R.; Fukazawa, Y. Chem. Commun. 2009, 2481-2483. doi:10.1039/b900599d

36. Xuan, W.; Zhang, M.; Liu, Y.; Chen, Z.; Cui, Y. J. Am. Chem. Soc. 2012, 134, 6904-6907. doi:10.1021/ja212132r

37. Gidron, O.; Ebert, M.-O.; Trapp, N.; Diederich, F. Angew. Chem., Int. Ed. 2014, 53, 13614-13618. doi:10.1002/anie.201406585

38. Koumura, N.; Zijlstra, R. W. J.; van Delden, R. A.; Harada, N.; Feringa, B. L. Nature 1999, 401, 152-155. doi:10.1038/43646 
39. Kassem, S.; van Leeuwen, T.; Lubbe, A. S.; Wilson, M. R.; Feringa, B. L.; Leigh, D. A. Chem. Soc. Rev. 2017, 46, 2592-2621. doi:10.1039/c7cs00245a

40. Roke, D.; Wezenberg, S. J.; Feringa, B. L. Proc. Natl. Acad. Sci. U. S. A. 2018, 115, 9423-9431. doi:10.1073/pnas.1712784115

41. Wang, J.; Feringa, B. L. Science 2011, 331, 1429-1432. doi:10.1126/science. 1199844

42. Zhao, D.; Neubauer, T. M.; Feringa, B. L. Nat. Commun. 2015, 6, 6652. doi:10.1038/ncomms7652

43. Chen, J.; Leung, F. K.-C.; Stuart, M. C. A.; Kajitani, T.; Fukushima, T.; van der Giessen, E.; Feringa, B. L. Nat. Chem. 2018, 10, 132-138. doi:10.1038/nchem.2887

44. Li, Q.; Fuks, G.; Moulin, E.; Maaloum, M.; Rawiso, M.; Kulic, I.; Foy, J. T.; Giuseppone, N. Nat. Nanotechnol. 2015, 10, 161-165. doi:10.1038/nnano.2014.315

45. Foy, J. T.; Li, Q.; Goujon, A.; Colard-Itté, J.-R.; Fuks, G.; Moulin, E.; Schiffmann, O.; Dattler, D.; Funeriu, D. P.; Giuseppone, N. Nat. Nanotechnol. 2017, 12, 540-545. doi:10.1038/nnano.2017.28

46. van Leeuwen, T.; Heideman, G. H.; Zhao, D.; Wezenberg, S. J.; Feringa, B. L. Chem. Commun. 2017, 53, 6393-6396. doi:10.1039/c7cc03188b

47. Zhao, D.; van Leeuwen, T.; Cheng, J.; Feringa, B. L. Nat. Chem. 2017, 9, 250-256. doi:10.1038/nchem.2668

48. McMorran, D. A.; Steel, P. J. Angew. Chem., Int. Ed. 1998, 37, 3295-3297.

doi:10.1002/(sici)1521-3773(19981217)37:23<3295::aid-anie3295>3.0. co;2-5

49. Chand, D. K.; Biradha, K.; Fujita, M. Chem. Commun. 2001, 1652-1653. doi:10.1039/b104853h

50.Su, C.-Y.; Cai, Y.-P.; Chen, C.-L.; Smith, M. D.; Kaim, W.; zur Loye, H.-C. J. Am. Chem. Soc. 2003, 125, 8595-8613. doi:10.1021/ja034267k

51. Neubauer, T. M.; van Leeuwen, T.; Zhao, D.; Lubbe, A. S.; Kistemaker, J. C. M.; Feringa, B. L. Org. Lett. 2014, 16, 4220-4223. doi:10.1021/ol501925f

52. Clever, G. H.; Shionoya, M. Chem. - Eur. J. 2010, 16, 11792-11796. doi:10.1002/chem.201002013

53. Sato, S.; Ishido, Y.; Fujita, M. J. Am. Chem. Soc. 2009, 131, 6064-6065. doi:10.1021/ja900676f

54. Macchioni, A.; Ciancaleoni, G.; Zuccaccia, C.; Zuccaccia, D. Chem. Soc. Rev. 2008, 37, 479-489. doi:10.1039/b615067p

55. Performed with the use of Bindfit software - http://supramolecular.com

56. Thordarson, P. Chem. Soc. Rev. 2011, 40, 1305-1323. doi: $10.1039 / \mathrm{c0cs} 00062 \mathrm{k}$

\section{License and Terms}

This is an Open Access article under the terms of the Creative Commons Attribution License (http://creativecommons.org/licenses/by/4.0). Please note that the reuse, redistribution and reproduction in particular requires that the authors and source are credited.

The license is subject to the Beilstein Journal of Organic Chemistry terms and conditions:

(https://www.beilstein-journals.org/bjoc)

The definitive version of this article is the electronic one which can be found at:

doi:10.3762/bjoc. 15.268 